\title{
Space Power Theory: A Tailor-made Approach or a New Theoretical Challenge to IR?'
}

This article aims to analyze U.S. space power theories formulated by eminent military strategists and analysts with reference to International Relations theories. Starting with the statement that space systems and space exploitation are becoming an increasingly important factor for states and non-state actors, the article seeks to explore if current space power theories meet the requirements of the changing reality. The main assumption of the article is that space power theories in their current form should be perceived rather as tailor-made doctrines formulated for strategic and political purposes, and not new IR theories, because they have many deficiencies. The article contains a review of basic theoretical attempts made by David E. Lupton, James E. Oberg and James C. Moltz, as well as a critical analysis of them in the context of IR. As a result, the article concludes that a comprehensive space power theory has not been formulated yet, and poses an academic challenge to IR theorists.

Space activities, previously marked by competition and the need for prestige, are nowadays based on the requirement for information in a globalized world. For this reason, economic development, and national and international security will be points of reference as far as space exploitation is concerned (Hays, Lutes 206-209). Therefore, some scholars suggest the need to define a theory of space power which "will provide an opportunity to maximize the benefits of space for global society" (Hays, Lutes 206). Samantha Marquart aptly points out that "space, unlike air and sea, is more than an operational zone; space's vast potential has yet to be reached" (Marquart 53). Brian E. Fredriksson also observes that there are several inherent advantages and disadvantages of space and space systems. Among the advantages he names global presence and

1 This article was written as part of the research project entitled European Space Policy (N N116 321638) funded by the National Science Centre. 
a global perspective, as well as a near instantaneous response and global persistence. There are also several disadvantages of space systems, such as the lack of physical terrestrial presence, predictable orbits, inhospitable environment and difficult access (distance/cost). Moreover, there are some neutral qualities of space systems such as destructive power (as for all forms of military power), range (global for all forces), destructive potential, and the risk of casualties (Fredriksson 37).

As a result, space power theory is being outlined because space security and exploitation have become key dimensions not only for space-faring states but also for particular states and societies worldwide. This means that the international reality has changed and IR theory should follow it. The main assumption of the article is that space power theory in its current form should be perceived rather as a tailor-made doctrine formulated for strategic and political purposes, not a new IR theory, because it has many deficiencies. First of all, there is no established or universally recognized space power theory. Instead, there are several, mainly military, doctrines formulated by U.S. strategists and military analysts that complement each other, although emphasizing different aspects of space power status. Almost all space power theories are based on analogies to sea or air power, such as, for example, theories proposed by Martin E. B. France (2000), John G. Fox (2000), George and Meredith Friedman (1996), Donald R. Baucom (1992), and Colin S. Grey (1999). In this context, the "globalness" doctrine/theory elaborated by Brian E. Fredriksson, although still military in approach, seems to be more comprehensive (Fredriksson 2006).

Secondly, there are no widely known or recognized scientific terms or definitions, which makes the whole theory unclear and inapplicable to research or analysis. For example, Robert E. Larned introduced a rather narrow definition of space power emphasizing the inherent interplay between space power and national security strategy. According to him, space power "is the ability to exploit the civil, commercial and national security space systems and associated infrastructure in support of national security strategy" (Jusell 8). The authors of Space Power 2010 conceptualized a wider definition of space power in order to include non-state actors as well as their goals and ambitions concerning space exploitation. They defined space power as "the ability of a state or non-state actor to achieve its goals and objectives in the presence of other actors on the world stage through control and exploitation of the space environment" (Jusell 8). There are also military analysts who have defined it strictly militarily as the "capability to exploit space forces to support national security strategy and achieve national security objectives" (Jusell 8).

Thirdly, authors who have framed space power theory have focused on the instrumental role it should perform, ignoring explanation and prediction. Therefore, they have rather formulated strategic recommendations which do not result from a theoretical explanation and are not connected with scientific prediction. Damon Coletta, for example, underlines the interplay between space and deterrence. He mentions three basic models of behaviour: (1) space control; (2) space avoidance; and (3) space deterrence. According to Coletta,

\footnotetext{
"space control seeks to ensure friendly access to space while denying that same assurance to hostile parties. Space avoidance reduces the problem by minimizing the need for U.S. presence in space. Finally, space deterrence attempts to harness the fear of an irrational, disproportionate response in order to dissuade would-be aggressors in space" (Coletta 173).
} 
Fourthly, as a tailor-made U.S. doctrine, space power theory is not applicable to analysis of space activities undertaken by other space actors. Finally, space power theory in its current form is deeply rooted in a realistic and military approach, which makes it inadequate for analysis of space policies and activities conducted, for example, by the EU and its member states. Samantha Marquart expresses this approach, stating that space power is now essential for conducting every military operation, because it provides key technologies to be used in the theater of operation as well as for intelligence and communication activities. Therefore, the U.S. is dependent upon space systems and applications, which in turn may give it an advantage over its opponents (Marquart 53).

Nevertheless, as Brian E. Fredriksson emphasizes, there is a need to develop a comprehensive space power theory, although it is not an easy task due to the fact that defining what a theory should do is easier than actually proposing a theory that meets these objectives (Fredriksson 42).

Therefore, the article will contain a review of basic theoretical attempts made by David E. Lupton, James E. Oberg and James C. Moltz, as well as a critical analysis of the space power theory in context of International Relations (IR). To quote Fredriksson again,

"the many commonalities [between space power theories] suggest fundamental truths about the nature of space power for political and military purposes. Together, they build from previous theories of military power, observations about the medium, efforts to categorize elements of systems, and projected means of employment. Yet, none build from a foundation that characterizes the fundamental nature of space power" (46).

\section{David E. Lupton's Space Power Doctrine}

David Lupton presents an influential theoretical approach towards space power. He defines space power as "the ability of a nation to exploit the space environment in pursuit of national goals and purposes and includes the entire astronautical capabilities of the nation" (Lupton 7). His definition is based upon three essential elements: national power, military and non-military goals, civilian and military space capabilities/systems. He proposes four detailed doctrines concerning outer space: "sanctuary," "survivability," "control" and "high-ground" doctrine.

First, space can be treated as a "sanctuary" because of the principle of "peaceful purposes." Yet it does not preclude the use of space in a non-aggressive way to support some military activities and goals, such as, for example, navigation, weather observation, communications, warning, etc. Yet space cannot be militarized and should be perceived as a war-free zone. A space system can support deterrence politics, and any step towards the militarization of space would be dangerous for existing space capabilities and assets which are indispensable for political and military goals.

Second, the "survivability" doctrine perceives space not as a strategic asset, but as an operational and tactical one. Space supports a warfighter, therefore giving an opportunity to gain additional advantage over an opponent. "Space begins to be considered a military center of gravity that needs protection to survive" (Gleason 13). Therefore, space systems and capabilities are perceived as vulnerable, 
requiring protection through defensive measures. Moreover, it is highly important that other actors should not have access to space. States or actors which are dependent on space systems can potentially pose many threats and their power status can be challenged if their access to space is denied.

Third, a "control" doctrine focuses on assuring access to space, protecting space infrastructure, and possessing the capability to deny space adversaries. Space is thus perceived as a strategic asset, yet a vulnerable one. As an ultimate high ground, space gives enormous potential for gaining an advantage over other areas on Earth. Therefore, in future wars, space will become a key battlefield. Space forces will play the most important role in future conflicts, and it is just a matter of time for states to acquire space weapons and military systems. A global presence as well as space-based weapons will therefore be essential for states in order to ensure their survival.

Fourth, the "high-ground" approach envisages that war can be waged using space as the ultimate high-ground in order to control the terrestrial theater of operation. Space forces and capabilities are perceived as similarly influential, although there is an assumption that whoever controls space also controls the terrestrial theater of operation. Moreover, it is presumed that the capability to control space results in the deterrence of war. It means the militarization of space, in other words (Gleason 13-14). This geopolitical assumption is extended by Everett Dolman in his Astropolitik concept. He formulated the dictum: "Who controls low-Earth orbit controls near-Earth space. Who controls near-Earth space dominates Terra. Who dominates Terra determines the destiny of the world" (Dolman 2002).

Lupton also introduces three unique attributes of space power: "environmentally influenced characteristics" such as global presence, quasi-positional sitting, congregational tendency, long-range electromagnetic weapon effects, hypervelocity kill, and infinite operating area; "logistically influenced characteristics" such as logistical handicap, inaccessibility, lack of manning, and altitude/security tradeoff; and "politically/legally influenced characteristics" such as legal overflight, vehicular sovereignty, and political insensitivity (Jusell 42).

According to Lupton, the "sanctuary" doctrine is not feasible because it does not take into account the reality, whereas the "high-ground" principle is not a good alternative for deterrence strategy in technological or political terms. As far as the "survivability" doctrine is concerned, he warns that there could be a risk of enormous costs which in turn could outweigh its advantages. Lupton suggests that the best doctrine is "control." To quote S. F. Swilley,

"key points to understand in Lupton's analysis include: control of a medium as a capability rather than a condition, restrict the lines of control during hostilities to specific areas of space, understand the line of advantage at the space boundary, apply centralized control to space forces, focus the use of space forces on the destruction of enemy space forces, and understand the operational tempo unique to space operations" (Swilley 15).

David Lupton's space power theory was a novelty when issued in 1988. Although his concept is state-centric, or more accurately U.S.-centric, he introduces the term "entire astronautical capabilities" to characterize space power, therefore expanding the narrow military definition used by strategists and military analysts. His definition concerns both military and civilian space assets and systems. Moreover, instead of the term state, Lupton uses the word "nation," which additionally underlines the strategic 
importance of space. He allows that space assets and systems be used for non-military purposes, for example to increase the well-being of citizens. Lupton's theory is methodologically well prepared, yet still it has more in common with military or political doctrine than with IR theory. The four schools of thought he introduced are inspiring, although cannot be used in academic research, since the author himself prefers one to the others. Doctrines cannot be used as theoretical models, therefore Lupton's concept cannot be labelled as theory in a scientific sense. One can have the impression that he started to formulate his space power concept by posing the question of why space power is important, and should start his question with "if."

\section{James E. Oberg and his space power theory}

James E. Oberg observes in his book entitled Space Power Theory that space power which is not combined with classic power determinants cannot ensure prompt results in terrestrial conflicts or the achievement of political objectives. Therefore, the control of space or space wars are, and will remain, important in upcoming years, especially as they pertain to terrestrial issues. He underlined that "space power must be combined with its emerging sibling, information power, and the older, purely terrestrial, expressions of national power" (Oberg 127). Oberg also points out that the militarization of space is inevitable, although one cannot predict its exact manner or time. J. E. Oberg expands the notion of space power by introducing elements such as facilities, technology, industry, hardware, economy, populace, education, tradition and intellectual climate, geography, and exclusivity of capabilities/knowledge (Fredriksson 43). Moreover, his vision is not state-centric, since he observes that any nation, organization or even individual can acquire space-derived "products." Therefore, the concept of space power is subjectively and objectively expanded and "de-militarized" because he discerns a commercial sector and non-military aspects of space power. Oberg's main assumption is that space, in a physical sense, is unique and cannot be compared with other spheres. The uniqueness of space can be used only when one has access to space and controls it, which in turn allows for exploitation. Moreover, the protection of space and space-based assets is also crucial for space power.

Oberg does not aspire to conceptualize a comprehensive space power theory in a scientific sense. Instead, he proposes a set of "truths" which are insightful assumptions on space power, enriching the whole discourse on it: (1) the main advantage of current space systems is that they allow a vast view of the Earth; (2) as a result, a space vehicle can be in sight of extensive areas of the Earth; (3) space should be perceived as a separate medium; (4) space power without other attributes of power status is not enough to control the result of terrestrial conflict or to meet terrestrial political aims; (5) space power is unique in comparison with other attributes of national power because it has developed without human presence in space; (6) for any successful use of space power a situational awareness system is essential; (7) in order to provide greater situational awareness a presence of humans in space will be needed in the future; (8) to become a space power, a technological advance is required but the achievement of that status means that many technological benefits can be reached; (9) control of space is of the utmost importance for a national space power; (10) the militarization of space is inevitable; (11) scientific research and 
exploration have proven to be worthwhile; (12) space operations have been and will be capital intensive; (13) "there will be wild cards" (Swilley 17).

J. E. Oberg attempts to reconceptualize space power theory via the prism of geopolitics. There are many advantages of his conception, yet some of his arguments are not scientific-driven. Therefore, one can follow his main assumptions or reject them, believe in his "truths" or deny them. So the main argument against Oberg's theory is that it is not a firmly established medium-level theory, but a loose coupling of his thoughts. However, it should be underlined that most of his arguments are clear and convincing. The most curious assumption one can find in Oberg's concept is the inevitability of the militarization of space. Authors who refer to the militarization of space usually write that it cannot be excluded or that actors/states should take such a possibility into consideration. Yet none are as explicit about it as Oberg.

\section{James Clay Moltz and the concept of space security}

According to J. C. Moltz, space security involves preservation from both man-made and natural threats. He defines it as "the ability to place and operate assets outside the Earth's atmosphere without external interference, damage, or destruction" (Moltz 11). There are four main schools of thought concerning space security: 1. space nationalism; 2. technological determinism; 3. social interactionism; 4. global institutionalism (Moltz 23).

Space nationalism started after World War II, and was marked by large, government-run military space programmes realized by both the U.S. and the USSR. A realistic approach, great power rivalry and hostility between them spurred them on towards space exploration and exploitation. J. C. Moltz describes this era by quoting McDougall: "the international system absorbed space just as it absorbed the atom." The two superpowers did not want to limit themselves as far as space exploration and exploitation were concerned, which is why they perceived international treaties and agreements as useless. Therefore, cooperation was limited and possible only in areas which needed huge costs or very complicated technical assets, and neither side was interested in their deployment. Thus, space-faring powers adopted a "militaristic drive" concerning space in order to achieve a strategic advantage over their rivals, similar to the rivalry during the era of sea power, Moltz adds (Moltz 24-27).

Global institutionalism is a diametrically opposite approach to space nationalism. Space is perceived as a "sanctuary from world political conflicts." The main assumption of this approach is that it is possible to achieve international cooperation concerning the exploration of "another unknown environment." Moreover, shared scientific thinking and international norms and treaties would bring security in space rather than a new arms race: "humans might be able to live peaceably in space through new methods of transnational governance" (Moltz 27-31). Thinking in the spirit of global institutionalism, German scholar D. Wolter has proposed signing a new treaty concerning Cooperative Security in Outer Space and then establishment of a new international organization to implement that agreement. The main provisions of the new treaty would provide for the prohibition of destructive space weapons, including ASAT, space-strike weapons, and antiballistic 
missile technologies, as well as an international system of monitoring and verifying provisions.

Technological determinism is focused on technological determinants not related to political factors. In the U.S. in the 1950s, many scientists believed that space exploitation, like nuclear energy, could raise standards of living. Pessimists, on the other hand, underlined the fact that military space technologies could lead to conflict and even space destruction (in space and from space). Therefore, the costs and complexity would make different states cooperate within the realm of space exploration/exploitation. The technological challenges were almost the same for states with "space ambitions." Technological determinism stresses the special role of a military-industrial complex as well as a "scientific-technological" elite in the process of space exploration/exploitation (Moltz 31-37).

In the 1970s and 1980s, the European political economy produced a variation of technological school thinking - a theory of "collective (public) goods." States interested in space activities were perceived as "self-interested rational actors making decisions according to shifting economic and strategic calculations." Commercial and military benefits from space exploration/exploitation could even lead to the "privatization of space." It could be possible because, apart from the U.S. and the USSR, different states and organizations interested in space activities appeared at that time. Nowadays, technological determinism is sometimes used by military scholars who refer to space as another important Revolution in Military Affairs (RMA). Some of them share the view that space militarization is inevitable, but it should not take the form of an aggressive arms race. Negotiations with other space powers are still important in order to reduce the probability of space conflicts (Moltz 34).

The newest approach towards space security is social interactionism. It is based on the assumption that new cooperative initiatives are possible, and a less military-oriented approach towards space exploration/exploitation is viable. Social interactionists have rejected the assumption that one has to accept the inevitability of space weapons, and have pointed out that there are plenty of political tools available for space-faring states which could be used instead of the deployment of harmful weapons, which could only "damage other priorities they had in space." Sometimes social interactionism is linked with concepts of cognitive change (learning) at the individual, organizational, and state levels (Moltz 37-40).

J. C. Moltz's conception of space security, although exhaustive, is not a comprehensive space power theory. His main arguments are convincing and clear from the methodological point of view, yet his overall approach is deductive and based on analysis of previous space experiences and activities. Therefore, he does not propose a model which can be used to conduct research on current and future space issues and space power in particular. Four schools of thought elaborated by him allow researchers to sort out his/her assumptions on space matters, but they are not analytical tools which can be used for qualitative research. Moreover, his conception is state-centred, ignoring the role of sub-state entities and non-state actors concerning space issues. Apart from the definition of space security, he does not introduce any other definitions and terms which can be useful for further analysis of space-related issues. Nevertheless, it should be underlined that his space security conception is interesting, clearly formulated, and without doubt an influential contribution to the debate on space power theory. 


\section{Conclusion}

It was assumed at the beginning of this article that space power theory in its current form should be perceived rather as a tailor-made doctrine formulated for strategic and political purposes, not a new IR theory, because it has many deficiencies. J. J. Klein observes that "despite these previous efforts to develop a comprehensive theory and strategy of space warfare, it has been observed that such a strategic framework - one encompassing the essence of space operations and associated national interests - has yet to be formulated" (Klein 3). Therefore, space power theory poses a scientific challenge to IR theorists. First of all, it should be framed by IR theorists, not military analysts, in order to avoid any military connotations. ${ }^{2}$ Moreover, comprehensive space power theory should be abstract in order to serve as a neutral scientific tool. It should be comprised of clear assumptions as well as specific wordings and terms. Descriptions, explanations, and predictions should be key functions of the theory, whereas its instrumental role should be a secondary one. As J. J. Jusell rightly pointed out, "space power theory is immature in its development of definitions, explanations and predictions of the nature, significance and functioning of space power" (Jusell 9).

If new space power theory is developed, some novelty compared to previous theoretical attempts should be included, because another attempt to build the theory via analogy to sea or air power is not enough, and, more importantly, comprehensive space power theory must allow for some generalizations. ${ }^{3}$ As was mentioned several times in this article, space power theory has to be applicable not only to the analysis of U.S. space policy and activities but also other state and non-state actors' purposes, behaviour and undertakings in space. Previous attempts to conceptualize a comprehensive space power theory have not been fully successful because it is not an easy task to invent a new paradigm in IR. However, theorists may choose the other way and put space power theory into existing IR theories or connect it with security studies. J. J. Jusell observes that a comprehensive definition of space power should in particular include the following aspects: the ability to exploit and control space; the perception of space as a unique and separate environment; the purposes of space power (security, economic and political); entire astronautical capability; categories of space capability including national, military, civilian, and commercial (space-based, ground-based and launch systems); the space actor can be not only a state but also a non-state actor (Jusell 27).

One thing is certain - further intellectual debate over space power theory is needed because space exploitation is a fact, and space capabilities and assets give state and non-state actors a unique opportunity to exercise their influence and power, and to increase them. According to S. F. Swilley, "space exploration, commercial space endeavors, and space enablers serve as the core space activities associated with space power. These three core space power activities serve three distinct national processes: innovation, prosperity, and security" (Swilley 34).

Another step to be taken in order to re-conceptualize the theory should definitely be to "de-policitize" and "de-militarize" it, as well as making it more academic rigorous. Moreover, there are a number of open questions that future space power

\footnotetext{
On military theory see Winton.
}

3 See Sumida. 
theory should answer. First, who can have space power - every state or non-state actor involved in space activities, the most prominent ones who have both civilian and military programmes and systems, or those who are engaged in development of space weapons, thus pushing for the militarization of space? Second, space control, especially via space situational awareness, is crucial because space exploitation depends on it. Yet the basic question is still the same - where does space begin and end? Third, what are the relations between space security and national security? Fourth, is there any interplay between space power and other power dimensions political, military, economic, etc.? Fifth, is space power completely unique compared to land, sea, and air power, or is it just another dimension of state power?

None of the authors of existing space power theories claim that they are comprehensive theories. Nevertheless, if someone undertakes the challenge, he/she will also have to elaborate on space power as an extension of policy, the relationship between space power and technology, the space militarization process or mutual dependencies between international law and space power. Furthermore, comprehensive but medium level space power theory is needed. Therefore, the most important thing is the purpose of the theory, i.e. what it has to be elaborated for, and to what kind of actors' behaviour it should be applied. This is why the main assumption of the theory should be widely recognized and placed on the continuum between narrowly understood national security and "colonization of the universe." Currently, space power is strictly a link with terrestrial power and political relations on Earth. Yet further progress as far as space exploitation and exploration of space is concerned may change this. It cannot be excluded that space relationships will influence and shape terrestrial affairs and relationships in the future. It should also be stressed that nowadays any attempt to analyze relations in space is done by extrapolation of constitutive elements of existing IR theories, and space power is now linked with geopolitics, realist and liberal theory, as well as constructivism. ${ }^{4}$ As R. L. Pfaltzgraff, Jr. aptly points out, "because space power enables and enhances a state's ability to achieve national security, IR theory will be deficient if it does not give space more prominent consideration. In the decades ahead, space power theory and IR theory will draw symbiotically on each other. It is increasingly impossible to envisage one without the other" (Pfaltzgraff 5). He envisages also that "the inclusion of space in IR theory will evolve as we incorporate space into national security because IR theory, like social science theory in general, is contextual" (Pfaltzgraff 5).

E. Sadeh, in the edited volume entitled Space Strategy in the 21st Century. Theory and Policy, and J. Sheldon in the book Theory of Space Power. The Perils of Strategic Analogy (published by Routledge in November 2012 and April 2013, respectively) broaden the intellectual discourse on space power theory. The main aim of E. Sadeh's volume, as declared on the publisher's webpage, is to identify "a number of areas of concern pertinent to the development of national space strategy, including: intellectual foundations; political challenges; international cooperation and space governance; space assurance and political, organizational, and management aspects specific to security space strategy." J. Sheldon's statement sounds even more promising. He declares that his new book "will provide a coherent strategic theory for space power, and explain why previous attempts at theorizing about space power have failed."

\footnotetext{
4 See Pfaltzgraff.
} 


\section{References}

Baucom, Donald R. Clausewitz on Space War: An Essay on the Strategic Aspects of Military Operations in Space. Maxwell AFB: Air University Press, 1992.

Coletta, Damon. "Space and Deterrence." Astropolitics vol.7, no. 3, 2009: 171-192. http:// dx.doi.org/10.1080/14777620903372982.

Dolman, Everett C. Astropolitik: Classical Geopolitics in the Space Age. London and Portland: Frank Cass Publishers, 2002.

Fox, John G. Some Principles of Space Strategy (or 'Corbett in Orbit). Washington DC: National Defense University National War College, 2000.

France, Martin E. B. Mahan's Elements of Sea Power Applied to the Development of Space Power. Washington DC: National Defense University National War College, 2000.

Fredriksson, Brian E. Globalness. Toward a Space Power Theory. Maxwell AFB: Air University Press, 2006.

Friedman, George and Meredith. The Future of War: Power, Technology, and American World Dominance in the 21st Century. New York: St. Martin's Griffin, 1996.

Gleason, Michael P. "European Union Space Initiatives: the Political Will for Increasing European Space Power." Astropolitics vol. 4, no. 1, 2006: 7-41. http://dx.doi.org/ 10.1080/14777620600762832.

Gray, Colin S. Modern Strategy. Oxford: Oxford University Press, 1999.

Hays, Peter L., Lutes, Charles D. "Towards a Theory of Space Power." Space Policy vol. 23, no. 4, 2007: 206-209. http://dx.doi.org/10.1016/j.spacepol.2007.09.003.

Jusell, Judson J. Space Power Theory. A Rising Star. Maxwell AFB: Air University Press, 1998.

Klein, John J. Space Warfare: Strategy, Principles and Policy. London: Routledge, 2006.

Lupton, David E. On Space Warfare: A Space Power Doctrine. Maxwell AFB: Air University Press, 1988.

Marquart, Samantha. "Space Power: A Unique Military Asset." International Affairs Review. vol. 20, no. 2, 2011: 47-54.

Moltz, James C. The Politics of Space Security. Strategic Restraint and the Pursuit of National Interests. Stanford: Stanford University Press, 2008.

Oberg, James E. Space Power Theory. Colorado Springs: US Air Force Academy, 1999.

Peter, Nicolas. "The changing geopolitics of space activities." Space Policy vol. 22, no. 2, 2006: 100-109. http://dx.doi.org/10.1016/j.spacepol.2006.02.007.

Pfaltzgraff, Jr., Robert L. "International Relations Theory and Spacepower," [in:] Lutes, Charles D., Hays, Peter et al. (eds.). Toward a Theory of Spacepower. Selected Essays. Web. 27 October 2012. http:/ / www.ndu.edu/press/lib/pdf/spacepower/space-Ch3.pdf.

Sumida, Jon. "Old Thoughts, New Problems: Mahan and the Consideration of Spacepower," [in:] Lutes, Charles D., Hays, Peter et al. (eds.). Toward a Theory of Spacepower. Selected Essays. Web. 27 October 2012. http://www.ndu.edu/press/lib/pdf/spacepower/space-Ch1.pdf.

Swilley, Scott F. Space Power: A Theory for Sustaining US Security Through the Information Age. Fort Leavenworth: School of Advanced Military Studies, United States Army Command and General Staff College, 2011.

Winton, Harold R. "On the Nature of Military Theory," [in:] Lutes, Charles D., Hays, Peter et al. (eds.). Toward a Theory of Spacepower. Selected Essays. Web. 27 October 2012. http:// www.ndu.edu/press/lib/pdf/spacepower/space-Ch2.pdf. 